\title{
Understanding Employment Opportunities and Challenges Facing Lao Graduates from Chinese
}

\section{Universities}

\author{
Soubin Sisavath ${ }^{1^{*}}$ \\ ${ }^{1}$ National University of Laos, Laos \\ ${ }^{1}$ Hiroshima University, Japan \\ "Correspondence: soubin@nuol.edu.la
}

\begin{abstract}
The purpose of this study is to explore the employment opportunities and challenges facing Lao graduates who studied abroad in China and returned home after graduation. A qualitative method was employed by utilizing semi-structured interviews with 17 Chinese-educated Lao graduates who now live in Laos. The findings revealed that although returning graduates were sought after in the local labor market, they seemed more employable in certain market segments in which China has been economically involved. Yet possessing a foreign degree alone was not sufficient to attain jobs unless it was complemented with foreign language fluency and employability skills such as communication skills and learning skills. The study also found that returning graduates tended to experience job mismatch and reverse culture shock in the process of their career development. With these findings, universities should sufficiently equip students with skills that can be effectively applied in different labor markets and contexts.
\end{abstract}

Keywords: student mobility, employment, job mismatch, culture shock, returning Laos graduates

\section{Introduction}

The trend of international student mobility is shifting. This has been witnessed by the increasing number of international students studying in Asia, resulting from the growth of intra-Asian regional

Received October 3, 2020; revised November 2, 2020, and November 20, 2020,; accepted November 27, 2020; electronically published January 31,2021

Journal of Comparative \& International Higher Education

December, 2020, Vol. 12, No. 6S1, pp. 142-151.

DOI: $10.32674 /$ jcihe.v12i6S1.2979

C 2020 Journal of Comparative \& International Higher Education. All rights reserved. 
mobility (Kuroda et al., 2018). One of the top Asian countries able to attract more international students is China. In 2018, China hosted nearly 500,000 international students, $60 \%$ were Asian students (Ministry of Education (MOE), 2019). However, little attention has been paid to international graduates' employability trajectories once they returned home (Lee \& Kim, 2010; Li, 2017). Even less known is whether education obtained from China helps in international graduates' career development upon graduation and returning to their home country. This research, therefore, aims to explore employment opportunities and challenges faced by Lao graduates from Chinese universities.

Laos is one of the largest source countries of international students for China. In 2018, there were 14, 645 Lao students studying in China (MOE, 2019). Meanwhile, China is one of the three largest source countries (China, Thailand, Vietnam) of foreign direct investment in Laos (Organization for Economic Co-operation Development, 2017). This is deemed important to Lao economic growth and create jobs for graduates. However, Lao higher education institutions have not yet produced highly qualified graduates to meet the skill requirements in the Lao labor market. Graduates lack both soft and hard skills required for employment (Del Carpio et al., 2013). Only 19\% of Lao graduates from local institutions are employed in the private sector, including foreign-owned companies, while the majority work for the public sector (Duronsoy et al., 2014). This opens job opportunities to foreign-educated graduates, particularly from China, but no previous studies have explored this area. Hence, this study intends to investigate it through these research questions: How does international education obtained in China affect Lao graduates' employment opportunities in the labor market in Laos? What are the key challenges faced by those graduates in career development?

\section{Theoretical Framework}

Human capital theory posits that schooling positively increases labor productivity and subsequently earning levels (Becker, 1993). Studying abroad is assumed to enhance graduate employability and productivity. Given foreign and domestic education are not homogeneous, studying 
abroad enables students to acquire both general and country-specific human capital (Wiers-Jenssen, 2008). Language skills, cultural and socio-economic knowledge of foreign countries are examples of country-specific human capital that can be acquired through studying abroad (Kim \& Park, 2013; WiersJenssen, 2008). Such country-specific skills give added value to graduates' degrees and are more applicable in a certain market segment than other areas. In the recruitment process, educational credentials send the signals of graduates' abilities and potential to employers (Spence, 1973). Thus, it is assumed that Chinese-educated Lao graduates will be attractive to employers and employed in organizations related to China.

\section{Methodology}

This study employed a qualitative method, which assists the researcher to gain more understanding of participants' experience (Silverman, 2006). A snowball sampling technique was used to approach participants, whereby the participants can recommend potential participants to the researcher to identify cases of interest and who are information-rich (Creswell, 2013). Seventeen graduates were invited to participate in this study. They all met these selection criteria: (i) held a degree obtained from China and (ii) had lived at least one year in Laos after graduation when this study was conducted. These criteria help ensure the participants meet the research purpose and have experience in labor markets. Their age ranged from 23 to 35 years old. More details on participants' demographics are provided in Table 1.

The research purpose and procedures of data use, i.e., anonymity and confidentiality, were clearly explained to participants. They were required to sign a consent form and complete a questionnaire before participating in semi-structured interviews. The interviews focused on participants' university-to-work transition experiences, current employment, and challenges. Due to the coronavirus pandemic, all the interviews were conducted via voice/video calls during June - July 2020. Conversations 
were audio-recorded for approximately 60 minutes with participants' consent. Nine of the participants were called back as follow-up interviews to clarify key points.

The interview responses were transcribed and analyzed using a thematic approach. First, all the transcripts were carefully read several times to make sense of the data. Coding procedures were done following Saldana (2013) when reading, the margin notes were marked, and initial codes were made. Then the data described were assigned codes and themes, followed by an iterative process to improve the interpretation and refine key points and understandings (Srivastava \& Hopwood, 2009). Finally, related themes were arranged into broad categories as key findings for the research questions and triangulated with the questionnaire data. Then, participants were invited to read through the paper as member checking and confirm accuracy. When reporting the interview responses, " $P$ " stands for "Participant", followed by an interview number (i.e., P1, P2).

\section{Table 1}

Demographic Information of Participants

Demographics Number of participants $(n)$

\section{Gender}

Female

Male

Degree

Master's

Bachelor

Place of residence

Vientiane Capital

Provinces

Disciplines 
Business

Social sciences

Education

Other

Employment status

Employed

Unemployed

Employment sector

Private

Public
4

\section{Preliminary Findings}

\section{Employment Opportunities}

This study found that foreign-educated graduates were sought after in the local labor market. Most participants obtained their first employment within one month of returning. This smooth transition was because they mostly looked for jobs in Chinese-owned companies in the local labor market so that their educational credentials, including Chinese language skills and institutional prestige, could send effective signals of their abilities and productive potential to employers. This showed that graduates take advantage of the leverage of the Chinese language, culture, and economic involvement in Laos to yield economic benefits. As one interviewee responded, "I found employment within one month in Chinese telecommunication company [...] Today, if you can speak Chinese well, you will get a job because there are many Chinese companies in Laos" (P12, personal communication, July 13, 2020). P12's comment reflected the extent to which Chinese educational credentials enhanced graduates' job opportunities in Laos. 
All participants, irrespective of their employment industries, agreed that employers prioritized language proficiency level, communication skills, intercultural competence, and ability to learn on-thejob over disciplinary knowledge when making recruitment decisions. One participant, who obtained a master's degree from a top-ranking university in China and is still seeking a job, admitted, "I failed many job interviews because my language skills and communication skills are not good" (P5, personal communication, June 10, 2020). This indicated that a foreign degree alone could not guarantee graduates employment despite graduating from a prestigious institution.

\section{Key Challenges Facing Returning Graduates}

\section{Job-Education Mismatch}

Although returning graduates were able to secure jobs quickly, many graduates were employed in jobs that are mismatched with their education undertaken abroad. They accepted job offers because employers offered a good salary and benefit in kind despite having irrelevant disciplinary knowledge and lacking prior work experience, that is because graduates could not do internships while studying abroad. Such compensation premiums actually traded on graduates' Chinese language fluency, degrees, and intercultural competence to learn on-the-job and introduce companies' products/services to local clients. As one participant explained:

I was recruited into a Chinese cement company because I speak Chinese fluently, but the job is about lab experiments and manufacturing, which differs from my major - international trade. I can use only language skills to communicate, learn new skills on-the-job with Chinese trainers and read online resources about my job [...] my parents told me to take any jobs available instead of staying unemployed (P16, personal communication, July 30, 2020).

Being educated abroad is perceived as a marker of social status and valuable cultural capital in Laos. P16's account also revealed that socio-cultural factors influenced job mismatches. If foreigneducated graduates are unemployed, they feel ashamed as in the Lao colloquial "Pa linnga the foun" 
(unemployed graduate walks on a dusty path). This evokes fear of losing face among graduates and their families. Therefore, graduates undertake whatever job offers there are to survive.

\section{Reverse Culture Shock}

Seniority and collectivistic working culture firmly remain in Lao society and workplaces, which many graduates found it difficult to readjust to. As one interviewee said, "I resigned from my first job with a local company to work for a Chinese company because I couldn't adapt to local work ethic and culture [...] like lack of commitment and punctuality" (P6, personal communication, July 28, 2020). P6's experience of difficulty in readjusting to local working culture implied that culturally specific skills and work ethic acquired abroad were more applicable in a certain workplace than other. While studying abroad, graduates could be trained to be critical, work-centered and competitive, but such skills and attributes might not fit in with their homeland context.

\section{Contributions of This Research to Comparative and International Higher Education}

This study contributes to the need to better understand international graduates' employability, particularly from Chinese universities. Foreign academic qualifications alone cannot guarantee graduates' employment and career development at home. Other employability skills such as interpersonal and communication skills, independent learning skills, problem-solving skills and adaptability are needed. Universities across the world may use the findings of this study to develop effective ways to sufficiently equip students with skills necessarily required to facilitate their job search and subsequent career development in different labor markets and contexts. This study also provides empirical information for future research to investigate more on the employability of international graduates from universities in Asia and compare with other regions.

\section{The Main Takeaway of This Research}

Graduating from Chinese universities enhances Lao graduates' employment opportunities at home, but they seem more employable in certain market segments where the country-specific human 
capital is in demand. In other words, their employability and career trajectories are significantly shaped by socio-economic aspects and relations between Laos and China. Yet returning graduates tend to experience job-education mismatch and reverse culture shock, which hinder them to realize full potential of their qualifications in the home country. In order to elaborate on these findings, the next steps for this research project will recruit more participants for a comprehensive survey and make a comparison between local graduates and Lao graduates from Asian and Western universities.

\section{Author Note}

Soubin Sisavath is a doctoral student in the Graduate School for International Development and Cooperation at Hiroshima University, Japan. His doctoral dissertation investigates the employability of international graduate returnees in Laos. The research focuses on university-to-work transition experiences, career outcomes, and challenges facing returnees in the domestic labor market. Employers' perspectives regarding employment and work are also integrated to substantiate the returnees' perspectives. Sisavath's other research interests include internationalization of higher education from the perspective of quality assurance and international students' experience, international student mobility in Asia, and university-industry collaboration. On a professional level, he has worked in the International Relations Office at National University of Laos, Laos, in charge of student and academic mobility for Asia and Europe. Correspondence address: Soubin Sisavath, 7939-5 Saijou Chou Jike, Higashi-Hiroshima, Hiroshima, Japan 739-0041.E-mail: soubin@nuol.edu.la.

\section{References}

Becker, G.S. (1993). Human Capital: A Theoretical and Empirical Analysis, with Special Reference to 
Education (3rd ed.). University of Chicago Press.

Creswell, J. W. (2013). Qualitative Inquiry \& Research Design: Choosing among Five Approaches (3rd ed.). Sage Publications.

Del Carpio, X., Ikeda, Y., \& Zini, M. (2013). Skills for quality jobs and development in Lao PDR: A technical assessment of the current context (Report No. ACS6593). World Bank Group.

Duronsoy, J., Syvilay, V., \& Billany, N. (2014). Report on tracer study on graduates' employability in Lao PDR. Strengthening Higher Education Project (Grant No. 0166-LAO). Ministry of Education and Sports, Laos.

Kim, J., \& Park, J. (2013). Foreign direct investment and country-specific human capital. Economic Inquiry, 51(1), 198-210.

Kuroda, K., Sugimura, M., Kitamura, Y., \& Asada, S. (2018). Paper Commissioned for the 2019 Global Education Monitoring Report, Migration, Displacement and Education: Building Bridges, Not Walls - Internationalization of Higher Education and Student Mobility in Japan and Asia (ED/GEMR/MRT/2018/P1/38). United Nations Educational, Scientific and Cultural Organization. https://www.jica.go.jp/jica-ri/publication/other/l75nbg000010mg5uatt/Background_Kuroda.pdf

Lee, J. J., \& Kim, D. (2010). Brain gain or brain circulation? U.S. doctoral recipients returning to South Korea. Higher Education, 59(5), 627-643.

Li, Z. (2017). International students' employability: What can we learn from it? In M. Tomlinson, \& L. Holmes (Eds.), Graduate Employability in Context: Theory, Research and Debate (pp. 195-211). Palgrave Macmillan.

Ministry of Education (MOE). (2019, April 18). Statistical report on international students in China for 2018. Ministry of Education, The People's Republic of China. http://en.moe.gov.cn/documents/reports/201904/t20190418_378692.html 
Organization for Economic Co-operation Development. (2017). OECD Investment Policy Reviews: Lao PDR. OECD Publishing.

Saldana, J. (2013). The Coding Manual for Qualitative Researchers (2nd ed.). Sage Publications.

Silverman, D. (2006). Interpreting Qualitative Data: Methods for Analyzing Talk, Text and Interaction (3rd ed.). Sage Publications.

Spence, M. (1973). Job marketing signaling. Quarterly Journal of Economics, 87(3), 355-374.

Srivastava, P., \& Hopwood, N. (2009). A practical iterative framework for qualitative data analysis. International Journal of Qualitative Methods, 8(1), 76-84.

Wiers-Jenssen, J. (2008). Career impacts of student mobility: Stumbling block or stepping stone? In $\AA$. Gornitzka \& L. Langfeldt (Eds.), Borderless Knowledge: Understanding the New Internationalisation of Research and Higher Education in Norway (pp. 79-101). Springer. 